\title{
Entrepreneurship
}

Jul a Dez $2018-$ v.2 - n.2

ISSN: 2595-4318

This article is also available online at: www.sustenere.co

\section{Gestão da diversidade: uma questão de responsabilidade social?}

Este artigo advém de intuito de instigar a busca e o desenvolvimento de mais pesquisadores e estudiosos, que visam ampliar a literatura da diversidade. Este estudo decorre sobre analisar estratégias a quais possibilitem lidar com a diversidade em um mercado supreendentemente evolutivo e agregar habilidades para que gestores tenham motivação para o desenvolvimento da diversidade e ampliar a visão de responsabilidade social das organizações. Com o objetivo de possibilitar o conhecimento aprofundado sobre a diversidade nas organizações através do aspecto evolutivo dos indivíduos com suas respectivas diferenças no ambiente organizacional. Sendo um estudo bibliográfico, toda a discussão teórica foi desenvolvida através de três pontos: o primeiro ponto fala sobre a contextualização e conceptualização do que é diversidade; no segundo ponto, são apresentados alguns tipos de diversidade que são decorrentes nas organizações; e o terceiro e último ponto ressalta a gestão da diversidade em quadrada na responsabilidade social, aonde vem falar da percepção moderna da diversidade e do enaltecimento da diversidade através da responsabilidade social. Infere-se que, necessário se faz que as empresas idealizem adaptações harmoniosas na esfera organizacional, assegurando integração dos indivíduos com suas diferenças.

Palavras-chave: Organização; Diversidade; Responsabilidade Social.

\section{Management of diversity: a question of social responsibility?}

This article comes from the intention of instigating the search and development of more researchers and scholars, who seek to broaden the literature of diversity. This study is about analyzing strategies that allow them to deal with diversity in a surprisingly evolutionary market and to add skills so that managers are motivated to develop diversity and broaden the vision of social responsibility of organizations. With the objective of enabling in-depth knowledge about the diversity in organizations through the evolutionary aspect of individuals with their respective differences in the organizational environment. As a bibliographical study, the whole theoretical discussion was developed through three points: the first point talks about the contextualization and conceptualization of what is diversity; in the second point, some types of diversity are presented that are derived in the organizations; and the third and last point emphasizes the management of square diversity in social responsibility, where it comes to speak of the modern perception of diversity and the enhancement of diversity through social responsibility. It is inferred that, it is necessary that the companies idealize harmonious adaptations in the organizational sphere, ensuring integration of individuals with their differences.

Keywords: Organization; Diversity; Social Responsibility.

Topic: Recursos Humanos

Reviewed anonymously in the process of blind peer.
Received: 11/02/2018

Approved: 12/04/2018
Cleyson Nathanael dos Santos

Faculdade Uninassau Aracaju, Brasil

cleyson.nathanael23@outlook.com

Helena Maria Fagundes dos Santos Braz

Faculdade Uninassau Aracaju, Brasil

http://lattes.cnpq.br/9373582225272500

hbraz81@gmail.com
Referencing this:

SANTOS, C. N.; BRAZ, H. M. F. S.. Gestão da diversidade: uma questão de responsabilidade social?. Entrepreneurship, v.2, n.2, p.44-53, 2018. DOI: http://doi.org/10.6008/CBPC2595-4318.2018.002.0004

DOI: 10.6008/CBPC2595-4318.2018.002.0004 


\section{INTRODUÇÃO}

A Gestão da Diversidade vem a ser o foco do presente artigo por conta da multiplicidade social dentro das organizações como também do relacionamento estreito com a Responsabilidade Social, uma vez que, esta "[...] vai além do cumprimento das leis, da prática filantrópica ou do apoio à comunidade, configurandose como responsabilidade cidadã, com direitos, mas, sobretudo, com deveres, atitudes que possam gerar valor para todos, com abrangência tanto para pessoa física quanto para jurídica" (PEREIRA, 2003). Para Toldo (2002), responsabilidade social é definida como "o comprometimento permanente dos empresários de adotar um comportamento ético e contribuir para o desenvolvimento econômico, melhorando simultaneamente a qualidade de vida de seus empregados e de suas famílias, da comunidade local e da sociedade como um todo".

Este artigo trata-se de um assunto de grande relevância dentro das organizações que é a gestão da diversidade, tema que gera fortes discussões entre gestores de empresas que buscam uma forma de lidar com suas equipes heterogêneas, e por essa razão, se norteará em analisar estratégias que possibilitam lidar com a diversidade em um mercado surpreendentemente evolutivo além de agregar habilidades comportamentais que motivem um desenvolvimento da responsabilidade social das organizações.

Analisar as relações sociais dentro das organizações, promover a reflexão sobre ideologia do conceito de Diversidade em âmbito organizacional e evidenciar a responsabilidade social através da diversidade, configuram-se nos caminhos percorridos para o alcance do êxito desse estudo. E levando em conta esse argumento pretende-se analisar e responder algumas dúvidas as quais serão norteadoras para a pesquisa, como: a gestão da diversidade é uma questão de responsabilidade social?

Justifica-se a realização desse estudo pela inclinação pessoal em ampliar os conhecimentos na área como também pela carência de trabalhos e artigos enquadrados na linha de raciocínio do tema apresentado. Trabalhar em uma organização heterogênea onde existem diferentes ideologias como, gêneros contrários, distintas identidades sexuais, pessoas com deficiências, nasce a possibilidade dos conflitos para gestores e impliquem na busca do desenvolvimento e da conscientização da responsabilidade social da sua organização, pois a multiplicidade em uma má administração da diversidade poderá resultar em um ambiente de indiferenças e discriminação com impactos negativos para o contexto organizacional.

\section{METODOLOGIA}

A investigação bibliográfica presente apresentou assiduidade de um intervalo em ligação à pesquisa executada de maneira determinada do mecanismo de gestão da diversidade nas organizações. A maior parte das organizações estabelece a diversidade como caraterística social e igualitária. Segundo Lakatos (2003, p. 83), "a metodologia da pesquisa é o conjunto das atividades sistemáticas e racionais que, com maior segurança e economia, permite alcançar o objetivo - conhecimento validos e verdadeiros - traçando o caminho a ser seguido, detectando erros e auxiliando as decisões do cientista". A pesquisa, além de provocar 
indagações e reflexões referentes à Gestão da Diversidade e à Responsabilidade Social, permitiu uma análise bibliográfica a qual o artigo de maneira indutiva vem apresentar.

\title{
DISCUSSÃO TEÓRICA
}

\section{Diversidade}

O Instituto Ethos (2000) conceitua diversidade como consoante conclusiva das indagações convenientes à integridade dos indivíduos. Desse modo, a diversidade caracteriza determinado advento das procedências dos direitos e deveres dos cidadãos os quais objetivam possibilidades a todos de oportunidades de amplo crescimento de suas competências.

\begin{abstract}
A diversidade é norma da espécie humana: seres humanos são diversos em suas experiências culturais, são únicos em suas personalidades e são também diversos em suas formas de perceber o mundo. Seres humanos apresentam, ainda, diversidade biológica. Algumas dessas diversidades provocam impedimentos de natureza distinta no processo de desenvolvimento das pessoas (as comumente chamadas de "portadoras de necessidades especiais"). Como toda forma de diversidade é hoje recebida na escola, há a demanda óbvia, por um currículo que atenda a essa universalidade. (LIMA, 2006)
\end{abstract}

Segundo o estudioso Thomas (citado por NKOMO et al., 1999), a diversidade inclui todos, não é algo que seja definido por raça ou gênero. Estende-se à idade, história pessoal e corporativa, formação educacional, função e personalidade. Inclui estilo de vida, preferência sexual, origem geográfica, tempo de serviço na organização, status de privilégio ou de não privilégio e administração ou não administração.

Fleury (2000) define diversidade como o resultado da interação entre indivíduos com diferentes identidades e que convivem no mesmo sistema social. "O tema diversidade cultural pode ser estudada sob diferentes perspectivas: no nível da sociedade, no nível organizacional e no nível do grupo ou indivíduo" (FLEURY, 2000).

Muito se discute sobre as questões da Diversidade a qual possui grande amplitude em todas as conjunturas sociais. No entanto, as alterações sobre o caráter demográfico de um determinado grupo social e do estímulo da força do trabalho apresentam instigado com finalidade de gerir os indivíduos. As mudanças no quadro econômico mundial e comercial, da mesma fora desenvolveu a capacidade de se dedicar a raça e costumes. Ao introduzir essas coisas aos acontecimentos na atualidade os indivíduos têm que convivem com conceitos referentes à heterogeneidade almejando a aceitação e a consideração cabível por suas diferenças (HANASHIRO et al., 2005).

Fleury (2000), o tema diversidade é recente surgindo nos anos noventa e os programas de gestão da diversidade são subsidiários de empresas americanas por imposição da matriz, preocupadas com a necessidade de gerar vantagens competitivas.

Os brasileiros valorizam sua origem diversificada, incluindo raízes africanas, presentes na música, na alimentação, no sincretismo religioso, gostam de se imaginar como uma sociedade sem preconceitos de raça ou cor. Mas por outro lado, é uma sociedade estratificada, em que o acesso às oportunidades educacionais e às posições de prestígio no mercado de trabalho é definido pela origem econômica e racial. (FLEURY, 2000) 
A interpelação sobre o tema Diversidade caminha tem sua caminhada a partir dos pareceres circunscritos às indagações sobre raça, etnia, gênero, idade orientação sexual, formação religiosa ou social, necessidades especiais. Inclusive maior parte da dimensão que reptam como diversidade todas as desigualdades particulares em meio às pessoas.

Fleury (2000) ainda afirma que "há diversos aspectos a serem considerados ao se pensar no que significa diversidade: sexo, idade, grau de instrução, grupo étnico, religião, origem, raça e língua". Isocronamente que a asserção sobre diversidade torna globalizante na iminência que reputa quaisquer especificidades de um determinado indivíduo.

\section{Tipos de Diversidade}

Hitt et al. (2013) dizem que diversidade se refere a peculiaridade de determinado grupo de indivíduos que seja encontrada consideráveis diversidades. Na contemporaneidade encontram-se profusos tipos de Diversidade em derredor do mundo, as preponderantes são: Diversidade de gênero, Diversidade de raça, Diversidade de etnia, Diversidade de orientação sexual. Ordinariamente as diversidades são demonstradas pelas pessoas através de concepções que levam a originar um pré-conceito em coma de um determinado ser ou aglomerado de indivíduos por conta de suas peculiaridades.

\section{Diversidade de Gênero}

Frisa-se que a Diversidade de Gênero desempenha o papel de correlacionar as notáveis analogias ou habilidade que advêm no convívio do homem e da mulher, não obstante no contexto organizacional, porem em toda a esfera social.

A questão de gênero toca as nações de masculinidade e feminilidade, o que é ser masculino e feminino, como educar e ser educado, e construir uma identidade produzida pela cultura e sociedade, impregnada de atributos, privilégios e limitações, com explicações para as diferenças baseadas em características biológicas. As relações de gênero produzem uma distribuição desigual de poder, autoridade e prestígio entre as pessoas de acordo com o seu sexo. (MACÊDO et al., 2004)

"Com os movimentos feministas, o(a)s estudioso(a)s das questões das mulheres deram novos significados à palavra Gênero" (SILVEIRA, 2010). Com isso, a indagação do termo gênero prontamente polemizado profusamente transcorre mais de um século, a transversalidade de prática assertivas, a mulher uma vez que se introduz progressivamente no âmbito empresarial, mas toda via essa perspectiva ainda não exterioriza equidade no convívio entre os gêneros.

Moreira et al. (2010) afirmam que "qualquer explicação manipulada pela ideia de gênero de modo que leve a crer que seja antagônico e contingente de sexo, conforme aquilo que aparece aberto e arquitetado em controversas num qual seria biologicamente incontestável, gênero é um termo conveniente com o objetivo de intitular as formas do homem e da mulher no vocabulário". De acordo com Olinto (1998),

Gênero é um conceito das Ciências Sociais surgido nos anos 70, relativo à construção social do sexo. Significa a "distinção entre atributos culturais alocados a cada um dos sexos e à dimensão biológica dos seres". O uso do termo gênero expressa todo um sistema de relações que inclui sexo, mas que transcende a diferença biológica. $O$ termo sexo designa somente a caracterização genética e anátomo - fisiológica dos seres humanos. 


\section{Diversidade de Orientação Sexual}

Habitam em uma sociedade rotulada por preconceitos oriundos as formações culturais as quais desde seus princípios implantaram ideias no seio da sociedade, ideias essas que devem ser reformuladas para um convívio em uma sociedade contemporânea a qual possui a sua própria forma de pensar e de agir. Na visão de Meyer et al. (2008) indaga que as pessoas as quais se esquivam do "padrão" social heterossexual ou até mesmo dos preconceitos de conduta social, isto, ou melhor, os homossexuais e bissexuais, que são retratados como pessoas oriundas de uma doença. No sentido de heterossexualidade é o estado sexual supostamente correto.

De acordo com Freitas et al. (2012) aduzem que os fatos históricos evidenciam que a partir do horto da colonização as intimidades homossexuais tornarem-se local onde havia uma junção das culturas indignas e europeias. A espontaneidade a qual os indígenas realizavam os atos homossexuais cativou o fascismo escandalizado dos portugueses. Doravante a orientação sexual irá proceder a um caminho que construirá a formação de identidade notada pela diversidade.

\section{Diversidade Étnica- Racial}

Cunha Junior et al. (2007) relatam que se encontram aqui no Brasil alguns impedimentos que dificultam a introduzir e a debater a diversidade dos afrodescendentes e sobre as discriminações raciais que até então transpassam o corpo social brasileiro. Pois, no momento o qual são estudados acontecimentos da construção social brasileira, consegue-se interpretar as conjunturas as quais interferem no desenvolvimento contemporâneo do corpo social. Todavia, essa projeção interfere na posição robusta do negro na sociedade e, por meio disto, o corpo social do Brasil denota aspectos diversificados com relação a essa projeção da sociedade. Sposati (2002) afirma que

o reconhecimento e a efetivação, com igualdade, dos direitos da população, sem restringir o acesso a eles nem estigmatizar as diferenças que conformam os diversos segmentos que a compõem. Assim, equidade é entendida como possibilidade de as diferenças serem manifestadas e respeitadas, sem discriminação; condição que favoreça o combate das práticas de subordinação ou de preconceito em relação às diferenças de gênero, políticas, étnicas, religiosas, culturais, de minorias etc.

Para Hitt et al. (2013), a descriminação concerne a comportamento contrário e improcedente que se firma com indivíduos ligados a comunidades sociais e culturais. Uma vez que a inclusão do negro no ambiente organizacional foi expressamente definida a partir das diferenças raciais dos indivíduos, sobretudo o que se refere as empresas no contexto empresarial brasileiro, o qual o negro sofre profusos ensejos de preconceitos de maneira cautelosa, mas com indagações de motejos preconceituosos de caráter racial.

\section{Diversidade Religiosa}

$\mathrm{Na}$ esfera religiosa brasileira, coabitam considerais crenças e heranças religiosas de matriz africana e indígena. A multiplicidade existente diante da relação entre o sagrado compõe a fundamentação cultural dos povos no que reflete as transcrições das práticas continuadas pela sociedade, se estabelece um suntuoso princípio de ciência a estimular a banal geração. Maduro (1983) considera como, "religião é uma estrutura 
de discursos e práticas comuns a um grupo social referente a algumas forças (personificadas ou não, múltiplas ou unificadas) tidas pelos crentes com anteriores e superiores ao seu ambiente natural e social.".

No entanto, a diversidade religiosa tende a se tanger somente aos indivíduos de outro modo a prática súbita, entretanto em sua conjuntura advém de particularidades com relação a riquezas e valores, entretanto, "tradição e cultura não podem servir de pretextos para restringir conviç̧ões e suas manifestações legítimas" (SILVA, 2007). Durkheim (1996) relata que

Todas as crenças religiosas conhecidas, sejam simples ou complexas, apresentam um mesmo caráter comum: supõem uma classificação das coisas, reais ou ideais, que os homens concebem, em duas classes, em dois gêneros opostos, designados geralmente por dois termos distintos que as palavras profano e sagrado traduzem bastante bem. A divisão do mundo em dois domínios que compreendem, um, tudo o que é sagrado, outro, tudo o que é profano, tal é o traço distintivo do pensamento religioso: as crenças, os mitos, os gnomos, as lendas, são representações ou sistemas de representações que exprimem a natureza das coisas sagradas, as virtudes e os poderes que lhes são atribuídos, sua história, suas relações mútuas e com as coisas profanas.

A laicidade do estado brasileiro veio coma à derrubada da monarquia e ascensão da República. 0 Catolicismo cessou sua "totalidade" de religião oficial do Brasil. No entanto a vigente constituição de 1988 expõe seus argumentos sobre religião decorrentes das cláusulas.

Apesar da coabitação de várias diretrizes religiosas sem vultosas conflagrações, na ocasião em que as diferenças sociais são persuasíveis e familiarizadas em meio aos individuais, é apontada pela autoridade habitualmente existente de discriminação e incessantemente a opressão religiosa.

\section{Diversidade de Pessoas com Deficiências}

Rodrigo et al. (2005) asseguram que portadores de necessidade especiais são todos aqueles indivíduos que retratam transitoriamente ou definitivamente danos ou degenerações de sua condição humana ou posição dos seus fenômenos mentais, fisiológicos, instruindo a estabelecer sua idoneidade com o objetivo de praticar suas laborações. As falhas limitantes denominadas como deficiência são representadas na maioria das vezes como, psíquico, auditivo, o estrutural que se refere a formação física do corpo e a visual. A Deficiência Física, nos termos do art. 4ํ do Decreto 3.298 de 20 de dezembro de 1999,

Trata da alteração completa ou parcial de um ou mais segmentos do corpo humano, acarretando o comprometimento da função física, apresentando-se sob forma de paraplegia, paraparesia, monoplegia, monoparesia, tetraplegia, tetraparesia, triplegia, triparesia, hemiplegia, hemiparegia, ostomia, amputação ou ausência de membro, paralisia cerebral, membros com deformidade congênita ou adquirida, exceto as deformidades estéticas e as que não produzam dificuldades para o desempenho de funções (BRASIL, 1999).

Conforme Branco et al. (2012), existem controvérsias que pleiteiam a aspiração de construir uma sociedade abrangente a qual venha tratar pessoas com igualmente4 sem visar qualquer diferença, e assim debelar com problemas atuais e implantar uma geração inclusiva. Os indivíduos portadores de deficiência se defrontam com as variadas noções sobre comportamento das outras pessoas que se difundem ao longo de tantos estágios incorporando ao ambiente de melhorias.

No entanto, de acordo com Costa (2013), a Lei 8.213/91 transcreveu a criação do processo exclusivo de cotas para deficientes adentrar como mais facilidade no mercado de trabalho com especificidade em 
empresas privadas. Esta lei designa que as organizações que possuem de 100 ou mais colaboradores é exigida que $5 \%$ desse quadro sejam revertidos para deficientes. Nota-se que esse regulamento objetiva a aspiração do estado em proteger de forma coerente os colaboradores e, evidenciar que a retenção de taxa de oportunidades de trabalho em estabelecimentos públicos para deficientes e admiti-los por empresas privadas e quede forma alguma o princípio da igualdade seja infringido.

\section{Gestão da Diversidade}

Conforme Fleury (2000), gestão da diversidade refere-se à difusão da multiplicidade da diversidade da força do trabalho, atribui avantajadas convicções relacionadas à competitividade das organizações. Alves et al. (2004), determinam a definição, ao estabelecer que gerir a multiplicidade organizacional, isto é, analisar por meio de habilidades empresariais, o desenvolvimento complexo dos grupos entende-se por uma técnica organizacional direcionada a coleta de oportunidades do mercado.

A gestão da diversidade nas organizações atribui-se a um feedback a uma gradual multiplicidade da expansão da potencialização da mão de obra, porém, com isso as possibilidades na demanda por competitividades (COX et al., 1991).

O Instituto Ethos (2000), evidencia que a gestão da diversidade expressa diversas vantagens as quais desenvolve os pros de oportunidades competitivas excitação do funcionamento de trabalho, a otimização da produção, desenvolvimento do bem-estar no trabalho, minimização da instabilidade da personificação empresarial. Alves et al. (2004) consideram que a gestão da diversidade é uma vantagem para as organizações e estabelece uma analogia que se refere aos prós originados as organizações, atribuições sociais específicas:

Primeiro, programas internos de empresas voltados à diversidade seriam socialmente mais justos do que políticas de Ação Afirmativa (AA) - impostas por uma legislação que remonta às lutas por direitos civis nos Estados Unidos durante as décadas de 1960 e 1970 - uma vez que se baseiam na meritocracia e não no favorecimento. Segundo, um bom gerenciamento da diversidade de pessoas nas organizações conduziria à criação de vantagem competitiva, o que, em tese, elevaria o desempenho da organização no mercado, tendo em vista a influência positiva de um ambiente interno multicultural, com membros de distintas experiências e habilidades.

No que diz respeito ao gerenciamento da Diversidade, Schimidt (2007) diz que a gestão da diversidade é considera complexa, pois ao mesmo tempo em que a diversidade constitui um desafio para as organizações com inúmeros benefícios possíveis, ela gera conflitos intergrupais, que podem, inclusive, neutralizar algumas de suas vantagens. De acordo com Dessler (2003) afirma que "Gerenciar a diversidade significa maximizar as vantagens potenciais da diversidade e ao mesmo tempo minimizar suas barreiras potenciais - como discriminações e preconceitos".

Thomas (1990) evidencia que o gerenciamento reproduzido a partir da diversidade debita o enaltecimento dos indivíduos proporcionando a anuência não apenas de pessoas favorecidas, no entanto todas as categorias dos indivíduos inclusas nas empresas. Conforme o autor, a finalidade desse gerenciamento não é suficientemente conveniente para garantir um aprazado ponto, entretanto, instituir aperfeiçoamento considerável de todos os pontos, principalmente ao que diz respeito às dimensões e 
colocação de posturas, porem refere-se a uma indagação de persistência de atividades empresariais. Alves et al. (2004) falam que, "a gestão da diversidade precisa afirmar a própria existência da discriminação para se justificar, o que a coloca em tensão com a ideologia da democracia racial. Sem o reconhecimento da discriminação, não há sobre o que construir um discurso de igualdade de acesso ao trabalho".

\section{Gestão da Diversidade enquadrada no conceito de Responsabilidade Social}

De acordo com o Instituto Ethos (2000), a percepção moderna relacionada à diversidade, refere-se ao efeito das procuras de chances afins e de consideração à integridade dos indivíduos. Da mesma forma, que a diversidade caracteriza uma razão fundamental para a sociedade que tenciona possibilidade a toda uma conjuntura de desenvolvimento de seus recursos e competência. Embora a execução da ação da diversidade signifique a realização devidamente correta com referência às diferenças, estabelecendo conjunturas e cenários em que os indivíduos sejam capazes de realizar suas atividades em consonância com seus princípios.

A preocupação com o social passou a ser até uma questão de sobrevivência. É uma forma de marketing. A Responsabilidade Social pode ser definida como o dever da empresa de ajudar a sociedade a atingir seus objetivos. É uma maneira de a empresa mostrar que não existe apenas para explorar recursos econômicos e humanos, mas também para contribuir com o desenvolvimento social. É, em síntese, uma espécie de prestação de contas (LIMA, 2002).

A responsabilidade social abrange uma profusão de atividades e práticas posicionamento, cujo são capazes de salientar: o engajamento ético e o empenho das ações junto à melhoria da sociedade, o enaltecimento da diversidade no meio organizacional evidencia a importância da empregabilidade e o desenvolvimento profissional dos indivíduos.

Segundo Boger (2001), o comportamento das empresas direcionado a responsabilidade social de forma alguma inspira os gestores de modo que não abdique dos propósitos econômicos das organizações e, que leve em consideração a assegurabilidade das vantagens do proprietário.

Alves et al. (2004), no entanto, "destacam que a boa gestão da diversidade atrai bons resultados para a corporação mediante aspectos característicos das políticas de ações afirmativas". Que, no entanto, a contemporaneidade o enaltecimento da diversidade não é exclusivamente sobreposta às heterogeneidades dos grupos éticos, no entanto, da mesma forma é aplicada para diferenças entre: religião, pessoas com deficiência, idade, orientação sexual, gênero, isto é, o desenvolvimento desta prática tenciona evidenciar as diferenças no convívio das pessoas de maneira que não haja rejeição e exclusão dos indivíduos sociais.

\section{CONCLUSÃO}

Este artigo foi elaborado para auxiliar aos atuais e futuros gestores de empresas com o objetivo de aprofundamento de conhecimento da diversidade dentro das organizações, buscando os benefícios de como administrar a multiplicidade da diversidade. 
Constatou-se neste presente estudo que a responsabilidade social das organizações advém como administrar a diversidade como um desenvolvimento e transformação e a versatilidade das empresas e as alterações do contexto organizacional.

Esse estudo cumpre a sua responsabilidade de replicar o problema da pesquisa e idealizar a maneira com a qual a diversidade desenrola-se dentro das organizações, no ponto de vista inclusivo. Deste modo, recomenda-se que as organizações idealizem adaptações harmoniosas na esfera organizacional, assegurando integração dos indivíduos com suas diferenças. Mediante argumentos, preconiza novas pesquisas sobre o tema apresentado com intenção de averiguar convicções sobre as instigações às quais as organizações se deparam ao buscar adequar-se aos parâmetros da diversidade.

A diversidade dispõe de encorajamento vindo das empresas e vem a favorecer um ambiente transformador. A diversidade nas empresas é uma condição altamente ponderosa para responsabilidade das organizações referente à diversidade no mercado de trabalho, considerando que os parâmetros os quais a organização assegura, são ambientes sociáveis para os diferentes indivíduos. Este estudo se formalizou através do objetivo geral de analisar estratégias que possibilitam lidar com a diversidade em um mercado surpreendentemente evolutivo, e agregar habilidades comportamentais que motive um desenvolvimento da responsabilidade social das organizações.

Todavia, que o direcionamento da gestão da diversidade refere-se a conceber a empresa um elevado desenvolvimento proporcionando o máximo de melhorias para os colaboradores e ocasionando um clima inovador de inclusão.

\section{REFERÊNCIAS}

ALVES, M. A.; SILVA, L. G. G.. A Crítica da Gestão da Diversidade nas Organizações. RAE, São Paulo, v.44, n.3, 2004.

BENTO, M. A. S.. Igualdade e diversidade no trabalho. Revista Latinoamericana de Estudios de Trabajo, São Paulo, v.5, n.10, p.89-120, 1999.

BRANCO, A. M. C. U. A.; OLIVEIRA, M. C. S. L. O.. Diversidade e cultura da paz na escola: contribuições da perspectiva sociocultural. Porto Alegre: Mediação, 2012.

BRASIL. Constituição da República Federativa do Brasil: 1988. Rio de Janeiro: Degrau Cultural, 1988.

COSTA, L. V.; CHIUZI, R. M. C.. Diversidade nas organizações: considerações dos trabalhadores sobre uma excelente empresa para se trabalhar. Revista Eletrônica Gestão e Serviços, São Paulo, v.2, n.2, p.337-359, 2011.

CUNHA JUNIOR, H.; RAMOS, M. E. R.. Espaço urbano e afrodescendência. Fortaleza: EdUFC, 2007.

DESSLER, G.. Administração de Recursos Humanos. 2 ed. São Paulo: Pearson Education Brasil, 2003.

DURKHEIM, E.. As Formas Elementares da Vida Religiosa. São Paulo: Martins Fontes, 1996.
FLEURY, M. T. L.. Gerenciando a diversidade cultural: experiência de empresas brasileiras. Revista Administração de Empresa, São Paulo, v.40, n.3, p.18-25, 2000.

FREITAS, M. E.; DANTAS, M.. Diversidade sexual e trabalho. São Paulo: Cengage Learning, 2012.

INSTITUTO ETHOS. Como as empresas podem (e devem) valorizar a diversidade. São Paulo, 2000.

INSTITUTO ETHOS. Perfil social, racial e de gênero das $\mathbf{5 0 0}$ maiores empresas do Brasil e suas ações afirmativas. 2003.

LAKATOS, E. M.; MARCONI, M. A.. Fundamentos de metodologia científica. 5 ed. São Paulo: Atlas, 2003.

LIMA, E. S.. Currículo e desenvolvimento humano. In: MOREIRA, A. F.; ARROYO, M.. Indagações sobre currículo. Brasília: MEC, 2006. p.11-47

LIMA, M.. Responsabilidade social: apoio das empresas privadas brasileiras à comunidade e os desafios da parceria entre elas e o terceiro setor. In: ETHOS. Responsabilidade social das empresas: a contribuição das universidades. Petrópolis: Instituto Ethos, 2002. p.103-142

MADURO, O.. Religião e luta de classes. 2 ed. Rio de Janeiro: Vozes, 1983. 
MOREIRA, A. F.; CANDAU, V. M.. Multiculturalismo:

diferenças culturais e práticas pedagógicas. 4 ed. Petrópolis: Vozes, 2010.

O'MARA, J.. Managing diversity. In: TRACEY, W. R.. Human Resources Management \& Development Handbook. New York: AMACON, 1994.

OLINTO, M. T. A.. Reflexões sobre o uso do conceito de gênero e/ou sexo na epidemiologia: um exemplo nos modelos hierarquizados de análise. 1998.

PEREIRA, R. S.. Responsabilidade Social na Universidade. Revista Gerenciais, São Paulo, v.2, p.113-125, 2003.

ROBBINS, S. P.. Comportamento Organizacional. 14 ed. São Paulo: Pearson Prentice Hall, 2012.

RODRIGUES, L. J.; CARMO, J. C.. A inserção da pessoa com deficiência no mundo do trabalho: o resgate de um direito de cidadania. São Paulo: Autores, 2005.
SCHMIDT, F.. A diversidade nas organizações

contemporâneas. Instituto Percepções de Responsabilidade Social, 2007.

SILVA, C. A.; RIBEIRO, M. B.. Intolerância religiosa e direitos humanos. Porto Alegre: Sulina; Metodista, 2007.

SPOSATI, A.. Mapa da exclusão: inclusão social. In: Políticas públicas: proteção e emancipação. 2002.

STEPHEN, P. R.. Comportamento organizacional. São Paulo: Pearson Prentice Hall, 2006.

THOMAS JUNIOR, R. R.. Redefining diversity. Human Resource Focus, v.73, n.4, 1996.

TOLDO, M.. Responsabilidade social das empresas: a contribuição das universidades. Petrópolis: Instituto Ethos, 2002.

A CBPC - Companhia Brasileira de Produção Científica (CNPJ: 11.221.422/0001-03) detém os direitos materiais desta publicação. Os direitos referem-se à publicação do trabalho em qualquer parte do mundo, incluindo os direitos às renovações, expansões e disseminações da contribuição, bem como outros direitos subsidiários. Todos os trabalhos publicados eletronicamente poderão posteriormente ser publicados em coletâneas impressas sob coordenação da Sustenere Publishing, da Companhia Brasileira de Produção Científica e seus parceiros autorizados. Os (as) autores (as) preservam os direitos autorais, mas não têm permissão para a publicação da contribuição em outro meio, impresso ou digital, em português ou em tradução. 